\title{
LOW-FLUX NEUTRON IMAGING
}

K. L. Swinth and L. L. Nichols
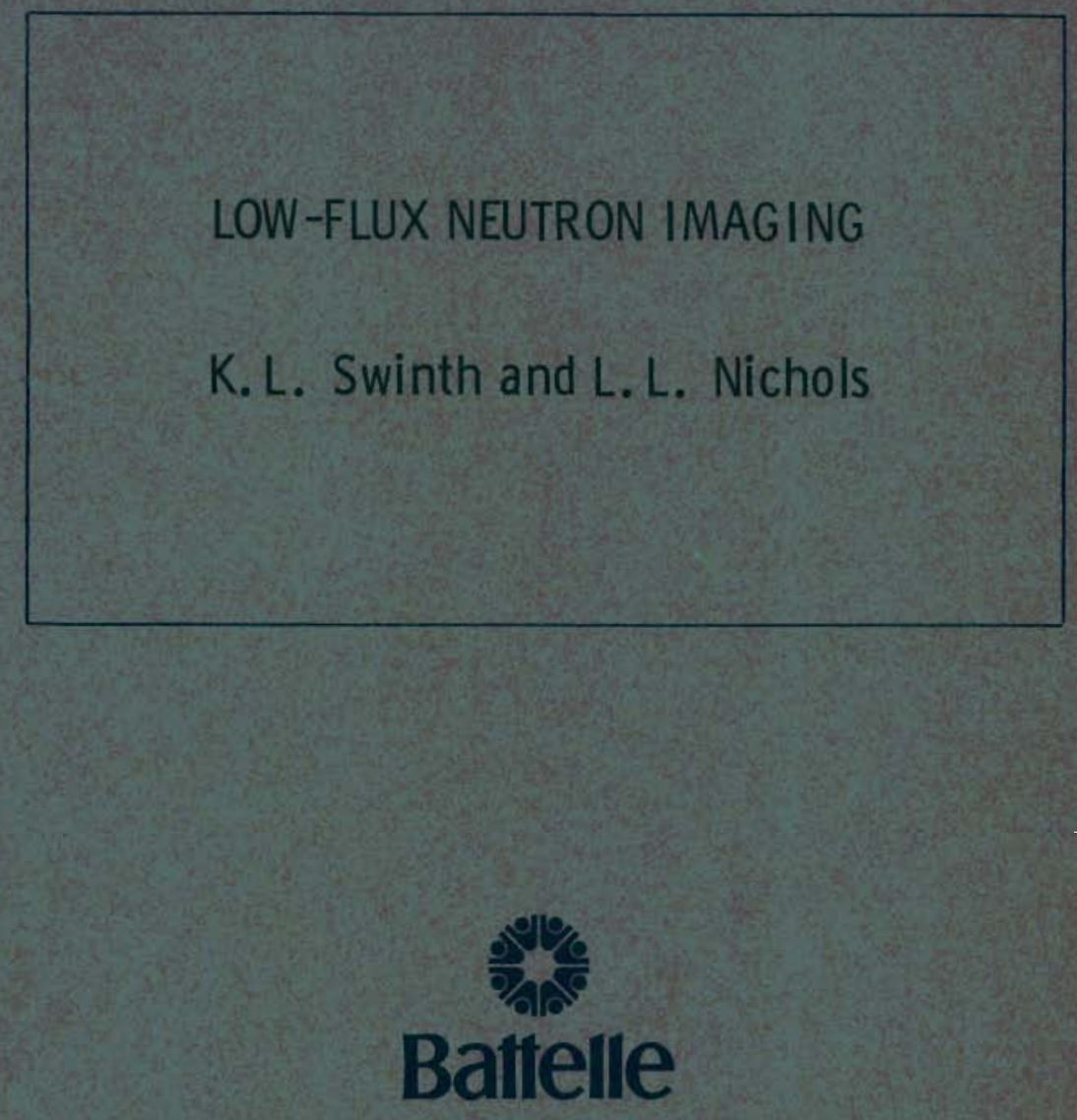

Pacific Northwest Laboratories

Richland, Washington 99352

\section{SEPTEMBER 1973}

Prepared for the U.S. Atomic Energy

Commission under Contract AT(45-1):1830 


\title{
NOTICE
}

The report was prepared as an account of work sponsored by the United States Government. Neither the United States nor the United States Atomic Energy Commission, nor any of their employees. nor any of their contractors, subcontractors, or their employees, makes any warranty, express or implied, or assumes any legal liability or responsibility for the accuracy, completeness or usefulness of any information, apparatus, product or process disclosed, or represents that its use would not infringe privately owned rights.

\author{
PACIFIC NORTHWEST LABORATORY \\ operated by \\ BATTELLE \\ for the \\ U.S. ATOMIC ENERGY COMMISSION \\ Under Contract AT(45-1)-1830
}

\author{
Printed in the United States of America \\ Available from \\ National Technical Information Service \\ U.S. Department of Commerce \\ 5285 Port Royal Road \\ Springfield, Virginia 22151
}

Price: Printed Copy \$4.00; Microfiche $\$ 0.95$

AEC-ML MICHLAND, WASH. 
33679000623084

BNWL -1770

LOW-FLUX NEUTRON IMAGING
K. L. Swinth
and
L. L. Nichols

September 1973

BATTELLE

PACIFIC NORTHWEST LABORATORIES

RICHLAND, WASHINGTON 99352 


\section{LOW-FLUX NEUITRON IMAGING}

K. L. Swinth and L. L. Nichols

\section{ABSTRACT}

Judicious use of scintillation screens greatly improves the capabilities for low-flux neutron imaging. Room temperature, cooled ${ }^{6} \mathrm{LiF}-\mathrm{ZnS}(\mathrm{Ag})$ and gadolinium oxysulfide $\left(\mathrm{Gd}_{2} \mathrm{O}_{2} \mathrm{~S}: \mathrm{Tb}\right)$ were evaluated for direct exposures, and $X$-ray intensifying screens were evaluated with dysprosium and europium transfer screens. Although gadolinium oxysulfide provides improved resolution, it requires seven times the imaging time of ${ }^{6} \mathrm{LiF}-\mathrm{ZnS}(\mathrm{Ag})$. Studies indicate that use of intensifying screens during transfer processes decreases the flux for a given density by about $30 \%$ and provides contrast enhancement. It was shown that cooling of scintillator-film combinations reduces reciprocity failure effects and in these experiments decreased direct exposure times $\left(\mathrm{Gd}_{2} \mathrm{O}_{2} \mathrm{~S}: \mathrm{Tb}\right)$ by up to $80 \%$. 
BNWL -1770

\section{LOW-FLUX NEUTRON IMAGING}

K. L. Swinth and L. L. Nichols

Film is a low efficiency recording medium. This fact is recognized in astronomy and techniques for hypersensitization of emulsions (baking, pre-exposure, and bathing in water or ammonia) and techniques for reducing reciprocity failure effects (cooling) have been developed. ${ }^{(1)}$ These techniques can be usefully applied to low-flux neutron radiography where reduction of exposure time is important.

A specially constructed cassette holder and vacuum cassette were built for exposures at a lower temperature as illustrated in Figure 1. The cassette is slid into the forward half of the exposure chamber where it is held in contact with an aluminum plate which is cooled by dry ice. The forward chamber is sealed during exposure and $\mathrm{CO}_{2}$ from the rear chamber is vented into this region to prevent moisture buildup on the cassette and object during exposure. The mass of the vacuum cassette is kept to a minimum to permit rapid temperature changes. Films are loaded and unloaded at room temperature and allowed to come to equilibrium at approximately $-10^{\circ} \mathrm{C}$ for exposure.

A number of different converters were employed in our investigations of low-flux imaging techniques including ${ }^{6}$ LiF-ZnS scintillators (NE 421 and NE $425^{*}$ ) and a gadolinium oxysulfide scintillator. (2) These scintillators with Kodak RP/R film were cooled for studies of the reciprocity failure effect. Exposure curves (Figure 2) were developed using the cooled cassette system with an effective collimation ratio of $27: 1\left(1.7 \times 10^{3} \mathrm{n} / \mathrm{cm}^{2}-\mathrm{sec}\right)$. For comparison, Figure 3 is a series of exposure curves for room temperature exposure. It takes one-third the time to reach a density comparable to a room temperature exposure using the ${ }^{6} \mathrm{LiF}-\mathrm{ZnS}(\mathrm{Ag})$ with the cooled system, while the improvement is a factor of 5 for the gadolinium oxysulfide scintillator. 
BNWL -1770

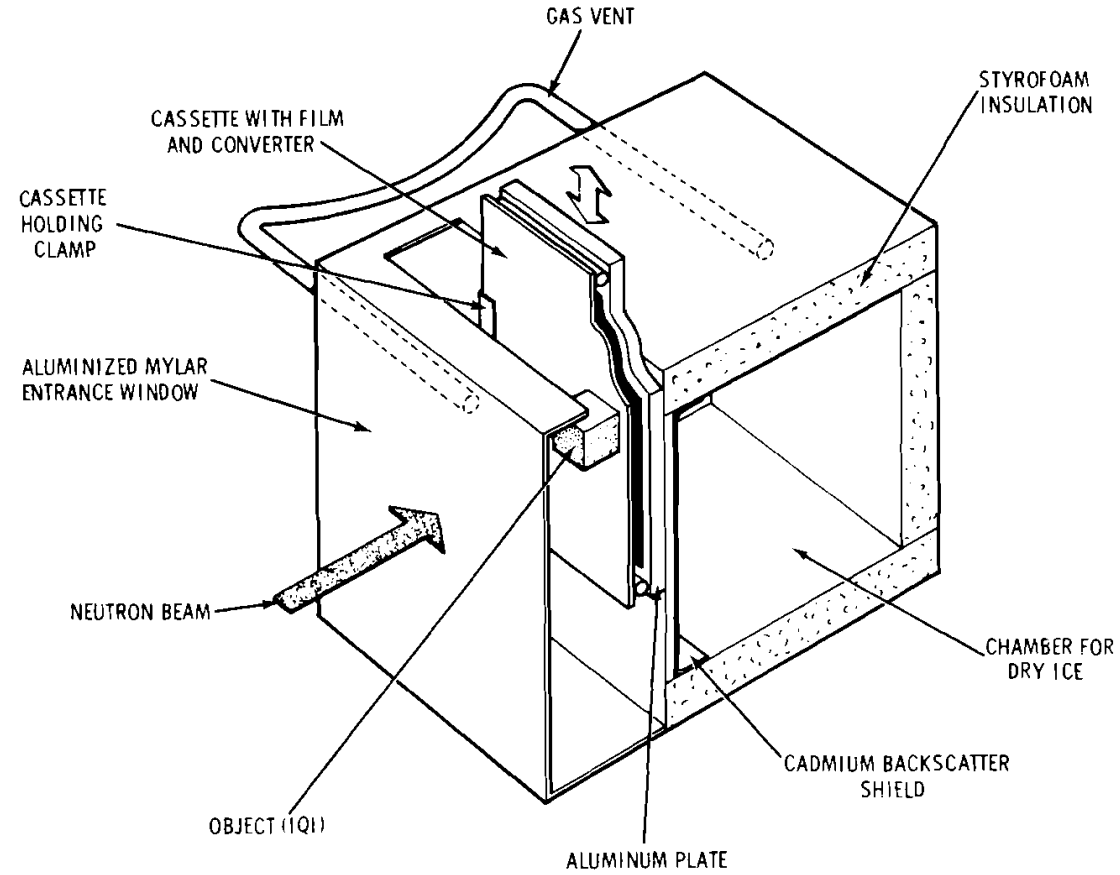

FIGURE 1. Cutaway Drawing of Dry Ice Box Used to Cool the FilmScintillator Combination During Exposure

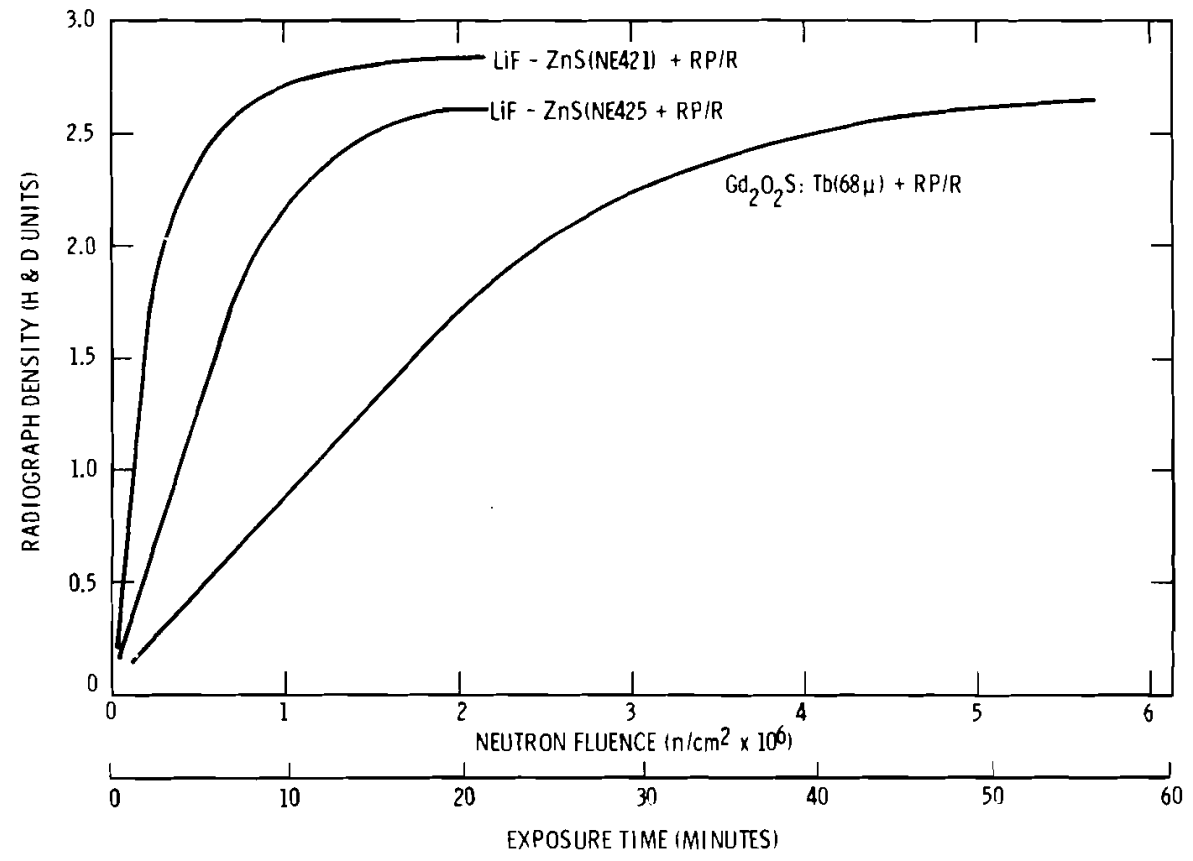

FIGURE 2. Radiograph Density Versus Exposure for Imaging Techniques When the Cassette is Cooled to $-10^{\circ} \mathrm{C}$ During Exposure. (The thermal flux was $1.7 \times 10^{2} \mathrm{n} / \mathrm{cm}^{2}-\mathrm{sec}$ and the col1imation ratio was about $27: 1$. ) 
BNWL -1770

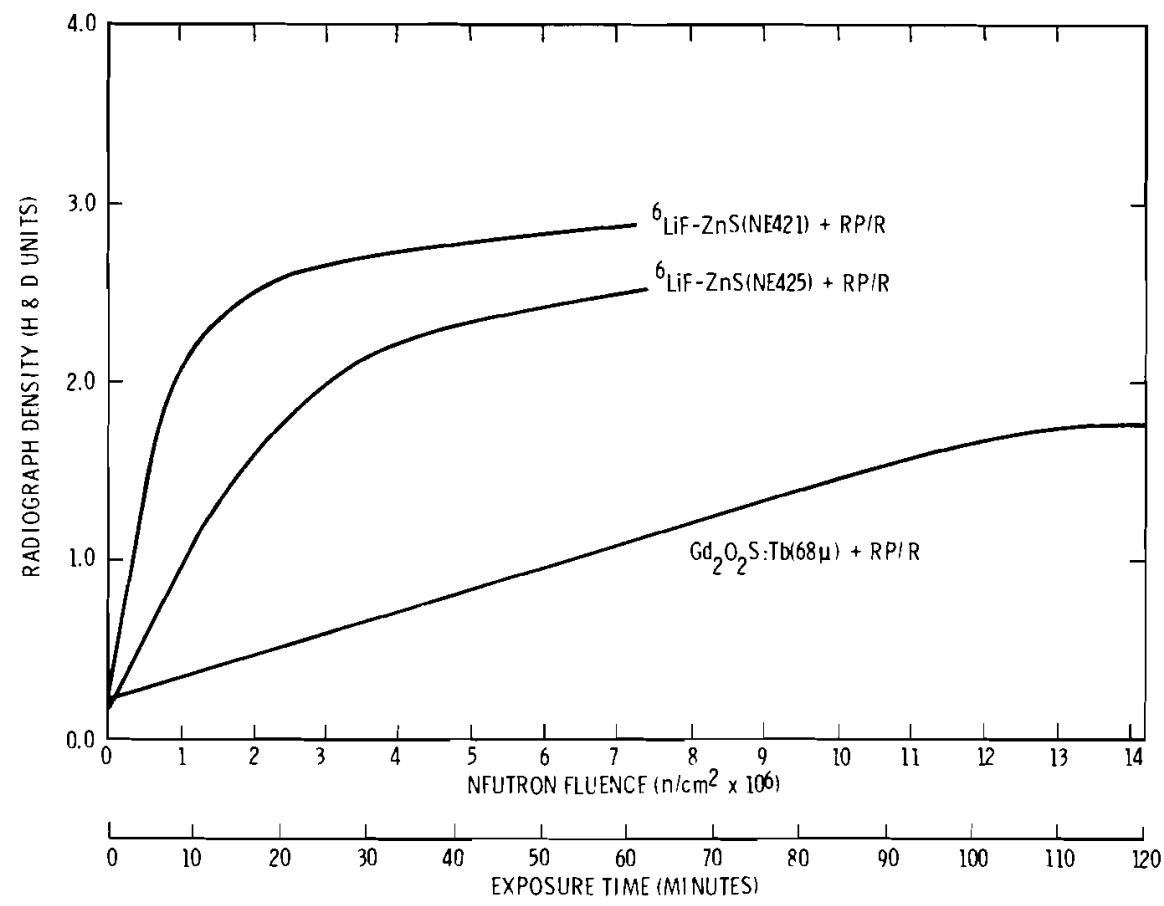

FIGURE 3. Radiograph Density Versus Exposure for Imaging Techniques at a Flux of $1.9 \times 10^{3} \mathrm{n} / \mathrm{cm}^{2}-\mathrm{sec}$ and a Collimation Ratio of 25:1

Reciprocity failure, as measured by the Schwarzschild index (1 for perfect reciprocity), is caused by a regression of sublatent image centers formed at low light levels. Cooling of the emulsion inhibits this regression, thus effectively increasing the speed of the film. There is an optimum temperature between $-20^{\circ} \mathrm{C}$ to $-100^{\circ} \mathrm{C}$ for emulsions used in astronomy; a similar optimum would exist in our case. Although we were probably above the optimum temperature $\left(-10^{\circ} \mathrm{C}\right)$, our results indicate the benefit to be achieved by cooling the film-scintillator combination.

By varying the collimation ratio between 15:1 to $40: 1$ a number of discrete flux levels were established. Exposures at the various flux levels were used to generate exposure curves to study the effect of flux level. Plots of exposure time versus flux level indicated at Schwarzschild index of 0.7 for Kodak RP/R film which is in agreement with the results of Hawkesworth. 
Development of imaging techniques for transfer radiography can be used to extend the usefulness of this technique to lower flux levels. This is important since transfer radiography is the only practical means of examining highly radioactive materials and such developments will permit the use of isotopic sources with their low fluxes. Sandwiching the film between the transfer screen (both $\mathrm{Eu}$ and $\mathrm{Dy}$ were used) and a $\mathrm{CaWO}_{4}$ scintillation screen during the transfer process enhances the film response (Figure 4 ). Further enhancement is achieved by cooling this combination as illustrated for dysprosium on Figure 4.

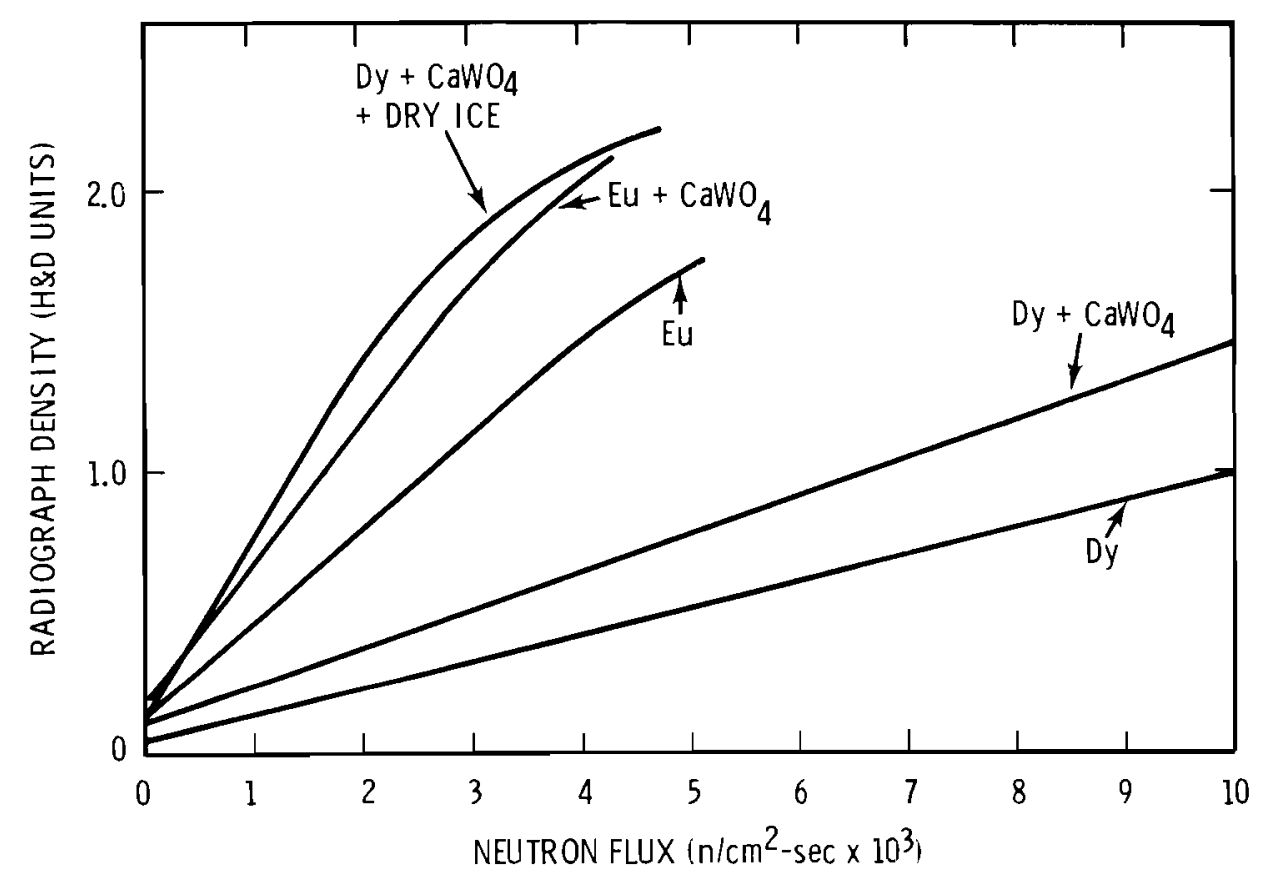

FIGURE 4. Radiograph Density Versus Flux Level for Europium and Dysprosium Transfer Imaging Using Kodak RP/R Film with and Without a Calcium Tungstate (CaW04) Intensifying Screen. (A curve is also shown illustrating the effect of cooling the film-scintillation combination during transfer.)

Optimization of imaging techniques is important for low-flux applications in order to provide reasonable results (time versus quality). Many potential applications for neutron radiography wi 11 increase interest as the technique becomes faster and more available to investigators. 
BNWL -1770

\section{REFERENCES}

1. A. A. Hoag and W. C. Miller, "Application of Photographic Materials in Astronomy," Applied Optics, vo1. 8, p. 247, 1969.

2. K. L. Swinth, "252 Cf Neutron Radiography at Batte11e-Northwest," Proceedings of the National Topical Meeting on the Applications of Californium-252 held in Austin, Texas, September 11, 1972, USAEC.

3. M. R. Hawkesworth, "Radiography with Low Intensity Neutron Beams: Some Reciprocity Failure Characteristics of Films Used with LightEmitting Intens ifying Screens," Journal of Physics E, vol. 2 (Series 2), p. 673, 1970. 
DISTRIBUTION

No. of

Copies

OFFSITE

1 AEC Chicago Patent Attorney

A. A. Churm

165 AEC Technical Information Center UC-23

ONSITE

15 Battelle-Northwest

J. F. Dawson

A. J. Haverfield/GJ Dau

I. C. Nelson

G. J. Posakony

J. L. Simmons

K. L. Swinth (6)

Technical Information Files

1 AEC/RL Patent Attorney

R. M. Poteat

2 AEC Richland Operations Office

H. House

B. J. Melton

Distr. 1 